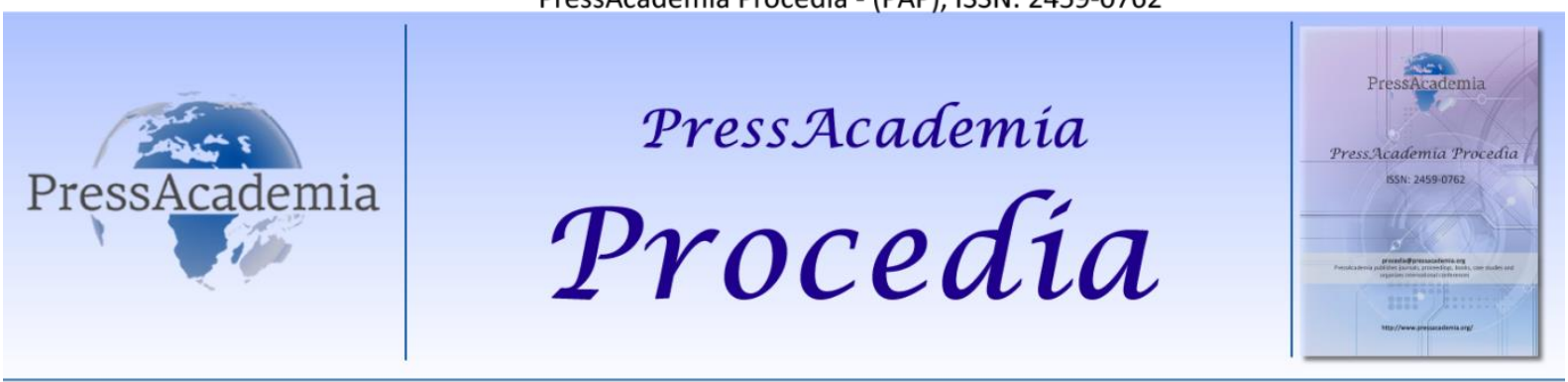

2nd World Conference on Technology, Innovation and Entrepreneurship

May 12-14, 2017, Istanbul, Turkey. Edited by Sefer Şener

\title{
INNOVATION APPLICATIONS AT IGDAS, A NATURAL GAS DISTRIBUTION COMPANY OPERATING IN THE ENERGY SECTOR
}

DOI: 10.17261/Pressacademia.2017.567

PAP-WCTIE-V.5-2017(5)-p.29-33

\section{Mehmet Akif Demirtas}

Manager of Stategic Planning \& Management Systems, IGDAS, İstanbul, Turkey

\begin{abstract}
In this study, the past, present and the future of innovation process in IGDAS (Istanbul Gas Distribution Industry and Trade Incorporated Company), which has been operating for 30 years as the biggest company of the intercity natural gas distribution sector of Turkey, are mentioned. In this regard, it can be expressed that it is also mentioned in a few published studies that include experiences with regards to collecting suggestions from internal and external resources on job development in the service sector related to electric, water and gas distribution ( utility sector ), and solving some problems, evaluating them, giving feedback, their implementation and awarding stages. In the notice, it was aimed at publicizing the company with its main field of activity, development, and some awards received, and afterwards, its innovation journey starting from the 2000s was explained via a case study approach, step by step, detailed under each title.
\end{abstract}

Keywords: Innovation, energy, natural gas, IGDAS

\section{INTRODUCTION}

Istanbul Gas Distribution Industry and Trade Incorporated Company (IGDAŞ) was founded on December 25, 1986, with the clear intent of saving Istanbul from air pollution, to conduct the intercity natural gas distribution works. Infrastructure works oriented towards this goal were conducted by the SAE consortium formed by French Sofregaz and Turkish Alarko companies, and natural gas started to be used in 1992. The ratio of sulfur dioxide in the air at that period, 219 micrograms $/ \mathrm{m}^{3}$, was threatening the human health, however, it caught a downwards trend as natural gas usage became widespread, and the ratio reached $20 \mathrm{micrograms} / \mathrm{m}^{3}$ in the beginning of 2000s, the limit level determined by the World Health Organization (WHO). As a result of the increased population in the city, energy consumption has increased in relation with the need for heating since the 1990s. Even though this was followed by the increasing number of vehicles and exhaust gas emissions, the above-mentioned ratio of sulfur dioxide has been kept at the single-digit level. This is a praiseworthy success. In a research conducted by Price Waterhouse Coopers (PwC) and an NGO called Partnership for New York City, in which the world's leading metropolises were evaluated under business life, daily life and innovation categories, Istanbul was successful to become one of the three metropolises with its air quality.

IGDAŞ, within the framework of the "sustainability" concept that it emphasizes both on its mission-vision and among its values, has been proceeding to become the flagship of the sector with its infrastructural investments and increasing number of subscribers, and has become a role model company in Turkey its sector with its maturing corporate model. As transparently shared from our website for years (Activity Report - 2015), more than 6 million BBS (number of independent units) subscribers are provided with 5.5 billion $\mathrm{m} 3$ of natural gas annually, via a natural gas line that is approximately 17.000 kilometers long, in a high quality, uninterrupted, and safe way. As a result of this, it has been among the top 20-30 companies of the biggest 500 companies of our country for the past 5 years. The concept of quality adopted by iGDAŞ has not only allowed the institution to ensure customer satisfaction, but also contributed to its becoming a structure that foresees continuous improvement and encourages employer motivation, and together with the understanding of quality it internalized with the participation of all its employees, the company adopted as a principle to evaluate the concepts of environment and work safety in a holistic manner.

It took the first step in its journey towards excellency by signing the goodwill declaration with KalDer (Turkey Quality Association) in 2007, with the aims of proceeding in accordance with its vision and strategic targets, focusing on the 
fundamental requirements and needs of its shareholders, forming future-oriented scenarios by determining their shortand long-term priorities, and managing the risks that may occur accordingly. IGDAŞ revealed its success with regards to the applied management model especially in the evaluations conducted by KalDer based on the EFQM (European Foundation for Quality Management) Excellence Model, by receiving 4 stars in 2009 on Competence in Excellence, Success Award in 2010, and National Quality Grand Award in 2011 in the Large-Scale Businesses category. The process was crowned with the Sustainability Excellence Award received in 2015.

So as to add value for the shareholders, works are monitored with an approach that is suitable with the logic of strategic planning, in relation with strategies, key performance indicators ( KPI ), activities, and process performance indicators concepts, studies to comply with customer satisfaction and corporate social responsibility principles are supported with survey results. Thanks to the different practices in relation with the process monitoring methodology and innovation works, these successes were crowned with the recently received 2011 Best Call Center (IMI Conferences), Corporate Social Responsibility Sustainability, and 2013 Company Adopting Customer Satisfaction As A Principle (Republic of Turkey, Ministry of Customs and Trade) awards. Moreover, the corporate maturity of iGDAŞ was openly proven with the Non-Public Company with the Highest Score Award received from Turkish Corporate Management Association in 2013, based on the rating about corporate management policies.

At this point, as mentioned at BUYEM (2014), intrapreneurship is an entrepreneurship approach maintained by all human resources in an established system and a functioning structure, and it is fundamentally an in-house open innovation approach. In this regard, the studies whose details are explained below and which were conducted within the framework of the strategical aim of strengthening the knowledge and technology leadership (technology, know-how, design, innovation) of IGDAS by improving its Innovation and Design capacity, which is among its strategical aims, provided added value in achieving the above-mentioned successes.

\section{IGDAS INNOVATION JOURNEY}

\subsection{Everyone's Opinion is Valuable}

As expressed by Kırım (2012), when innovation is considered, what is meant is not always the radical, Silicon Valley-style innovations. Any company in any sector should have a command on various types of innovation that they can put into effect in different situations and succeed, and especially the conditions under which these types give the best solutions. Starting from a similar point of view, suggestions began to be collected in 2001 so as to solve some problems faced during the business processes. Main logic here is the assumption that the person who conducts his/her work in the best way is the one who knows about it the most, and that he/she is the first one to encounter the problems and search for solutions. The environment in which the verbal ideas would, so to speak, evaporate in the beginning turned into a process in which written suggestions were collected, evaluated by a commission, and improvements, although gradually, started to be made. In this 3-year period, coordination was ensured by an administrative unit, and as the main area of activity of the company is natural gas distribution and as the received suggestions dominantly have a technical nature due to the technical background of most of the employees, the business was required to be conducted under the responsibility of a technical unit.

\subsection{Suggestion Evaluation}

From Adair's (2008) point of view; while innovation is organizationally a natural human activity, it should be as voluntary and planned as possible. If you fail to plan, you plan to fail. Based on the internationally accepted reality, one can suggest that an organization that avoids to face change or does not need innovation is doomed to stagnate, decay and, finally, die. Just as the trees start to die from the top, this saddening process in the companies starts from the top management and spreads towards those in the sub-levels. Managerial leaders are needed for a beneficial change program. Change swiftly increases the need for leaders. Leaders are those that will ensure change. Even though innovation is a natural process, it becomes more effective when led appropriately. This means that change shall be welcomed, planned, controlled, monitored, and most importantly, led in accordance with the aims of the organization. As stated in section 2.1., some technical problems could be solved thanks to the approach of a technical department that speaks the same language, and, when a possible resistance towards change is considered, the fact that the top management spread the change towards the employees, in the meaning of mentality, starting from itself, and made it systematic. In the period between 2004 and 2006, the number of the suggestion evaluation meetings increased, and the foundations of an archive, although manually, were laid.

\subsection{Suggestion Follow-up System}

Drucker (2003), who has various studies on innovation, defines the concept of innovation management as "the activities companies perform so as to conduct innovation under control within a process by activating both the unorganized and complex structure and their managerial activities in order to comply with the internal and external changes". When used by 
itself, the concept of innovation may express the process, however, the concept of innovation management expresses the controlling of innovation by means of managerial activities during implementation. Since 2006, advancement was contributed when a unit that is in close relation with the company plans, has both technical and administrative features when it comes to know-how, and that reports to the company's top management. The support of the top management allowed the problem of encountering some negativity during the implementation stage of the accepted suggestions to be solved faster.

\subsubsection{Solution at Work Practice}

Even though quality was increased thanks to the monthly suggestion-specific evaluations conducted by specialist assessors, if the desired number of suggestions were not reached, the following method may be applied: All employees may be asked via a letter written directly to the personnel by the top management (general manager of CEO) for a certain period of time (30-45 days, for instance) whether they have suggestions with regards to their own job. Thomas et al. (2000) expresses in a study that the objectives of the innovation process in companies may be listed as follows:

- $\quad$ Ensuring structural attitudes for systematic and continuous innovations,

- Defining environmental and legal possibilities and determining the ideas that may lead innovation,

- Determining financial and strategic objectives in order for the innovation effectiveness of the company.

With the Solution at Work project implemented in 2008, the results expressed in articles 1 and 2, namely the annual number of collected suggestions, were achieved in a short period of time - 1 to 2 months. At this point, the personnel desired not only to express the suggestion in black and white, but also verbally, in front of the team that evaluates it, and this was implemented.

\subsubsection{Digital Infrastructure Installation}

When Özdaşli's (2006) approach is considered, innovation process in organizations should not be left to coincidences, but be planned and foreseen. In order for innovation to be managed, it is required to determine and plan objectives that are really related to innovation, and the related plans to be implemented. So as to manage innovation in a planned way, it shall be realized that innovation is a process, and the stages of creating and obtaining new ideas in this process, as well as the stage of implementing these ideas shall be organized well. An innovative movement systematically implemented for companies may be effective. In this regard, especially within the scope of the EFQM excellency model works mentioned in the introduction part, companies experienced on innovation were visited on-site so as to learn and compare, and as a result, it was decided that a system shall be established, which is able to follow-up on the system from end to end, whose evaluation criteria were determined, feedback logic is settled, and which will also support the corporate memory. Therefore, a more professional process management is aimed at. Thanks to an easily usable-widespread module that is compatible with the digital system used within the company, the suggestions entered into the system are, if necessary, are pre-screened based on the announced criteria (compatibility with the main field of activity, added value to the company activities, originality, etc.). As a result of the evaluation meeting, the correspondence with the relevant units, award process, etc. information is recorded. Therefore, such a software support both supports the formation of innovative ideas and enables the managing of ideas with a portfolio logic.

\subsubsection{Innovation Volunteers' Team}

In the Uzkurt's (2008) work, Morgan argues that an innovative organizational culture can only be developed by means of a cultural change and transformation. O'Reilly, on the other hand, lists the necessary activities for such a change and transformation as follows:

- $\quad$ Ensuring employee participation in the process,

- Developing a management understanding that supports and motives change,

- $\quad$ Evaluating the internal and external information, and

- $\quad$ Establishing a comprehensive award system for the change-related activities.

Especially with regards to the issues mentioned in the first two articles, an announcement was made to all units and all stages, and an "Innovation Volunteers' Team" was formed with representatives from all units - from operators to managers. In order for the team to speak the same language, training was received about the subject, and suggestion evaluation works started to be conducted more systematically by means of this team. 
On top of that, as the information and culture level on the subject increased, the team organized works with special groups formed within themselves as with a project logic, on specific issues determined by the top management, and reported the results to them. Therefore, steps were taken not only towards gradual, but radical innovation.

\subsection{Innovation Management System}

Starting from the phenomenon of "change is the only constant", the established systems shall be improved in time, and be made more answerable to developing needs. In accordance with the demands of the employees that supported the innovation system with their suggestions and the ideas developed by the innovation volunteers, a new digital infrastructure was established in 2012, which is much more developed when compared to its 2008 version, through which the owner is able to follow up on his/her suggestion at any stage, by which repetitive/similar suggestions are detected and grouped more easily, and which has a pool that can be re-evaluated when the conditions change, even when the given suggestions were not accepted due to various reasons. In this period, the team of assessors that change based on the idea continued to work in the meetings led by the related assistant general manager, in which the owner is personally present to offer his/her suggestion. Moreover, the increase in the number of suggestions, namely quantity, was important in the previous periods, while today, the value added to the company with the suggestion, namely quality, has gained importance.

\subsubsection{Open Innovation}

Except for a standardized website allowing suggestions to be received externally, designing a solely innovation-oriented website is a practice that was again supported with the idea created by the innovation volunteers, and received acceptance of the top management. Therefore, an innovation communication channel was established, which is open to suppliers, subscribers, industrial users, and the world. Furthermore, a visual design called "inovig" was made for publicity purposes, and used in the website and other activities. The company's innovation website was awarded the Golden Ant Award in the Communication Management Projects category in 2012, given by Marmara Municipalities Union.

\subsubsection{Innovation Day Event}

As expressed in the EFQM Excellence Model, employees are appreciated, known and supervised. Excellent institutions encourage their employees to participate in the improvement and entrepreneurship process, and recognize their endeavors and successes. In this regard, the suggestion-owners who deserved to be awarded are done so according to the procedures and principles of the company on "giving awards and gifts to the personnel", by means of the periodical ratings conducted from the beginning. The issue is announced to the other personnel via appropriate communication channels. While these events can be conducted in-house, the award ceremony can be organized in an environment such as a university, where innovative products are displayed, narrated to the visitors by means of posters and LCD TV screens, and in which applications are performed via which the participators can have interactive roles, by learning especially from the events organized by international companies on this issue. This situation is also expressed as "people's contributions to the company are realized and valued" at the liP (Investors in People) - the award our company deserved to receive in 2015 standards, which are followed by few companies in our country.

\subsubsection{Spreading with Education in Innovation}

In 2014, together with the changes in the innovation volunteers' team, a comprehensive and professional training oriented at the "Conjoining with Innovation Coaching Bases and Company Innovation Process" for a more systematical spread of innovation culture within the company was received in collaboration with a rooted university, which enabled the team to renew itself and maturity level to increase with regards to the style in approaching the issue.

\subsubsection{Implementing and Monitoring the Suggestions}

As expressed in the previous sections, the suggestions which were decided to be implemented via the Innovation Management System Module is implemented by the related unit, its results are recorded in various dimensions, and monitored accordingly. In addition, the implementations can also be monitored within the framework of Strategic Planning, which has been efficiently implemented in the company for long years. The critical success factors of the strategic objectives included in the 5-year Strategic Plans are detected, and they are measured by means of key performance indicators (KPI). The activities that are annually updated so as to ensure these are monitored by means of performance target indicator and value during the review meeting of the management organized at each quarter of every year, and reported to the top management. Therefore, the appropriate suggestions originating from the Innovation Management System can naturally be evaluated within the scope of the above-mentioned strategic activity. 


\section{FINDINGS}

Evaluating the results of a conducted study/activity, receiving feedback via methods such as survey, and making improvements on the process, if necessary, are very good opportunities. Within the scope of the periodical Employee Satisfaction Surveys made with this purpose, questions on innovation activities were prepared, and how the issue is perceived by internal customers, namely the employees, began to be monitored. The results were entered into the process improvement module, and the related units were ensured to conduct necessary process improvements. Beneficial findings can be obtained via methods such as audit, evaluation or investigation. A professional off-site eye can evaluate you on different dimensions and compare you with your counterparts, and you may benefit from it. With this aim, the iGDAŞ Innovation Management System that was tried to be explained above in general terms was desired to be evaluated with a non-partial and systematic point of view. In 2014, InovaLiG was participated in, which is an innovation development program conducted by Turkish Exporters' Assembly (TIM) with the support of A.T. Kearney. During the first implementation of the competition, which is practiced in 17 European countries and based on the IMP rove methodology, in our country, the standards that were developed in Europe in years were complied with in a sensitive way. Among the 460 firms registered for the competition, our company ranked among the first 250 companies thanks to its data quality and the attention paid. When these are evaluated according to the A.T.Kearney "House of Innovation" methodology, the average points received by these companies were surpassed in the fields of innovation strategy, innovation organization and culture, and enabling factors. In this group, in which there are companies that keep innovation activities at the center of their main working field, have years of experience, and are well-known in their sectors, our company especially took justified pride of being among the top 5\% group in the "Enabling Factors" category.

\section{CONCLUSION}

The more a work, either in the social life or business life, is valued, the more success or beneficial result is obtained from it. The fact that the structures established in the companies are well-founded, systematic and integrated with other practices is among the essential factors of sustainability. The findings reported by an external observer, which are especially expressed in the third section, provide us with a good idea on the functionality of the established system. Therefore, it can be asserted that an innovation role model that can be implemented in the companies which operate in the utility sector is put forth. In this notice that was summarized above, an "Innovation Management System Model" implemented in a largescaled company operating in the natural gas distribution sector of the energy industry was shared with case studies.

\section{REFERENCES}

Adair, J. (2008). Yenilikçi Liderlik, (1st Edition), Istanbul

Büyem, 2014, “Boğaziçi University Lifelong Learning Center: Conjoining with Innovation Coaching Bases and Company Innovation Process Training Notes"

Drucker, P. F. , "The Discipline of Innovation”, Trans. Ahmet Kardam, Mess Yayınları, Istanbul, 2003, p. 120

İgdaş, 2015, “Annual Activity Report - 2015 ”

Kırım, A. (2012). Mor İneğin Akıllısı, (44th Edition), Istanbul

Kuczmarski , T., Middlebrooks, A., Swaddling , J., Innovating the Corporation: Creating Value for Customers and Shareholders, NTC Business Books/Contemporary Publishing Group, 2000, p.141

Özdaşlı, K., "Toplam Kalite Yönetimi ve Yenilik iliş̧kisi: Bir Örnek Olay”, AKADEMiK BAKIŞ Uluslararası Hakemli Sosyal Bilimler E-Dergisi, Issue: 10, September 2006, p.14

Uzkurt, C.; Yenilik Yönetimi ve Yenilikçi Örgüt Kültürü, Beta Yayınları, Istanbul, 2008 